\title{
DESIGN AND EVALUATION OF EXTENDED RELEASE CEFUROXIME AXETIL FLOATING TABLETS WITH IMPROVED GI ABSORPTION
}

\author{
Gaurav Singh Gurjar*, Mithun Bhowmick, Vaishali Rathi, Jagdish Rathi
}

NRI Institute of Pharmaceutical Sciences, Bhopal, India

\begin{abstract}
Oral drug delivery system represents one of the frontier area of controlled drug delivery system. Floating drug delivery system belongs to oral controlled drug delivery system group, which is capable of floating in the stomach for prolong period of time. The objective of the present research work is to provide a gastroretentive system for sustained release of therapeutically active agent, cefuroxime axetil in upper part of gastro-intestinal tract in the form of floating tablet. Cefuroxime axetil, an oral prodrug shows a bioavailablity of $30 \%$ to $40 \%$ when taken on fasting and $5 \%$ to $60 \%$ whentaken after food. The cefuroxim axetil esterase can hydrolyze cefuroximeaxetil to the nonabsorbable cefuroxim in the gut lumen and is therefore, suspected as a possible cause of incomplete bioavailability. Which suggests an absorption mechanism through the mucosa with limited capacity. Cefuroxime axetil had saturation kinetics that could be overcome by slow release of drug from the formulation, by incorporating cefuroxime axetil in sustained drug delivery system.
\end{abstract}

Keywords: Floating drug delivery system, Cefuroxime axetil, Gastro-intestinal tract

Article Info
Received 14 Nov 2016; Review Completed 14 Dec 2016; Accepted 27 Dec 2016, Available online 15 Jan 2017

Cite this article as:

Gurjar GS, Bhowmick M, Rathi V, Rathi J, Design and evaluation of extended release cefuroxime axetil floating tablets with improved G.I. absorption, Journal of Drug Delivery and Therapeutics. 2017; 7(1):49-59, DOI: http://dx.doi.org/10.22270/jddt.v7i1.1352

*Address for Correspondence

Gaurav Singh Gurjar, NRI Institute of Pharmaceutical Sciences, Bhopal, India, Email: gauravgurjarsrcp@gmail.com

\section{INTRODUCTION}

FDDS is also called Hydrodynamic Balance System (HBS) system, is an effective technology to prolong the gastric retention time in order to improve the bioavailability of drug. FDDS that float immediately upon contact with gastric fluid present promising approaches for increasing the bioavailability of drugs with absorption windows in the upper intestine.

An attempt has been made to systemically investigate the contribution of several formulation variables on the physico-chemical properties, in vitro drug release and floating properties of floating drug delivery system for absorption window limited drug with short half-life like, Cefuroxime axetil. Cefuroxime axetil (CA) is abroad spectrum B-lactamase cephalosporin that has well defined pharmacokinetics after intramuscular and intravenous administration in the form of sodium salt. In humans, gastrointestinal absorption of cefuroxime is negligible. Cefuroxime axetil had higher absorption in the proximal region of GI tract and poor absorption, as well as antibiotic associated colitis, when a large amount of drug entered the colon suggest it is an ideal candidate for a gastroretentive drug delivery system that will prolong the gastric residence time of the dosage form, giving prolonged drug release in the upper GI tract, where absorption of cefuroxime is well defined. $^{1-6}$ 


\section{MATERIAL AND METHODS:}

\section{Materials:}

The drug Cefuroxime axetil was received as a gift sample from Zeel Pharma, Mumbai, India. Hydroxy Propyl Methyl Cellulose- K4M, Eudragit RL-100 and Hydroxy Propyl Cellulose were obtained from Colorcon asia Pvt. Ltd (Goa, India), , Ethyl cellulose, Micro Crystalline Cellulose. Polyvinyl pylorridone, Sodium Bicarbonate, Citric acid, Iso Propyl Alcohol, Magnesium Stearate and lactose were obtained from SD Fine chemicals Mumbai, All the solvent used were of analytical grade.

\section{Methods:}

\section{Preformulation studies ${ }^{7-12}$ :}

\section{(a) Organoleptic properties}

The sample of cefuroxime axetil was studied for organoleptic characters such as color, odor and appearance.

\section{(b) Melting point}

Melting point was determined by open capillary method using melting point apparatus.

\section{(c) FTIR Spectroscopy}

The FTIR spectrum of Cefuroxime axetil was recorded using FTIR spectrophotometer (Shimadzu $8400 \mathrm{~S}$ ) using $\mathrm{KBr}$ pellet technique. The peaks are is shown in fig

\section{(d) UV spectroscopy (Determination of $\lambda$ Max)}

Stock solution $(100 \mu \mathrm{g} / \mathrm{ml})$ of cefuroxime axetil was prepared in $0.1 \mathrm{~N}$ HCL. This solution was appropriately diluted with $0.1 \mathrm{~N}$ HCL to obtain a concentration of 30 $\mu \mathrm{g} / \mathrm{ml}$. The solution was kept in a fused silica cuvette $10 \mathrm{~mm}$. The UV spectrum was recorded in the range of 200-400 nm on UV Visible Spectrophotometer (Shimadzu 1600)

\section{Calibration curve for cefuroxime axetil}

$100 \mathrm{mg}$ cefuroxime axetil was accurately weighted \&transferred to $100 \mathrm{ml}$ volumetric flask. It was then dissolved in $0.1 \mathrm{NHCL}$ and sonicated for $10 \mathrm{~min}$ \&diluted to volume with $0.1 \mathrm{~N}$ hcl to give stock solution containing $1000 \mathrm{mg} / \mathrm{ml}$. This solution was appropriately diluted with $0.1 \mathrm{~N}$ HCL to obtain a concentration of $5,10,15,20,25$, and $30 \mu \mathrm{g} / \mathrm{ml}$. The above solutions were analyzed by U. V. Spectrophotometer at $280 \mathrm{~nm}$. All the dilutions were made using $0.1 \mathrm{~N} \mathrm{HCL}$ was used as a blank during spectrometric analysis.

\section{(e) Differential scanning calorimetry studies}

Thermal analysis was performed using (DSC60 Shimadzu) system with a differential scanning calorimeter equipped with a computerized data station. All samples were weighed and heated at a scanning rate of $10^{\circ} \mathrm{C} / \mathrm{min}$ between 30 and $300^{\circ} \mathrm{C}$ and $40 \mathrm{ml} / \mathrm{min}$ of nitrogen flow. The differential scanning calorimetry analysis gives an idea about the interaction of various materials at different temperature. It also allows us to study the possible degradation pathway of the materials.

\section{(f) Determination of solubility}

Cefuroxime Axetil solubility study was carried out using saturation method.

\section{(g) Drug Excipients Interaction}

The possibility of any interaction between the drug and the carriers was detected by Fourier Transform Infrared (FTIR) spectroscopy and Differential Scanning Calorimetry (DSC).

Fabrication of Tablets ${ }^{13-19}$ :

Each floating tablets containing 250mg cefuroxime axetil were prepared by a conventional wet granulation method, employing sodium bicarbonate, citric acid as gas generating agent and different polymers in each formulation. Cefuroxime Axetil, Lactose and polymers were passed from sieve of \# 40 and mixed for $10 \mathrm{~min}$. Gas generating agent was then passed through sieve of \# 60 added to the above mixture. Binding solution of polyvinyl pyloridone was Prepared in Isopropyl alcohol. Dry at room temperature and pass from sieve of \# 40. Magnesium stearate was passed through sieve of \# 60 and added to the above mixture. The whole bulk of granules were then mixed thoroughly for $15 \mathrm{~min}$. The granules were then compressed to form a tablet.

Table 1: Table showing the formulation codes and polymer content

\begin{tabular}{|c|c|c|c|c|c|c|c|}
\hline Formulation Code & F1 & F2 & F3 & F4 & F5 & F6 & F7 \\
\hline DRUG (mg) & 250 & 250 & 250 & 250 & 250 & 250 & 250 \\
\hline HPMC K4M (mg) & 60 & -- & -- & -- & 30 & 30 & 30 \\
\hline ETHYL CELLULOSE (mg) & -- & 60 & -- & -- & 30 & -- & -- \\
\hline EUDRAGIT-RL-100 (mg) & -- & -- & 60 & -- & -- & 30 & -- \\
\hline HPC (mg) & -- & -- & -- & 60 & -- & --- & 30 \\
\hline NaHCO $3(m g)$ & 100 & 100 & 100 & 100 & 100 & 100 & 100 \\
\hline CITRIC ACID (mg) & 30 & 30 & 30 & 30 & 30 & 30 & 30 \\
\hline MG. STEARATE (mg) & 10 & 10 & 10 & 10 & 10 & 10 & 10 \\
\hline LACTOSE (mg) & 50 & 50 & 50 & 50 & 50 & 50 & 50 \\
\hline Total (mg) & $\mathbf{5 0 0}$ & $\mathbf{5 0 0}$ & $\mathbf{5 0 0}$ & $\mathbf{5 0 0}$ & $\mathbf{5 0 0}$ & $\mathbf{5 0 0}$ & $\mathbf{5 0 0}$ \\
\hline
\end{tabular}




\section{Evaluation of Granule Properties ${ }^{20-28}$ :}

The flow properties of granules were characterized in terms of angle of repose, Carr's index and Hausner's ratio.The bulk density and tapped density were determined and from this data Carr's index and Hausner's ratio were calculated.

\section{(a) Bulk density:}

Both untapped bulk density, $\rho_{u}$ (often called loose or aerated bulk density) and tapped bulk density, $\rho_{\mathrm{b}}$ were determined. A amount of powder blend was introduced in a $10 \mathrm{ml}$ measuring cylinder up to $9 \mathrm{ml}$ volume.Then the weight of powder blend was determined by substracting the weight of empty measuring cylinder from final weight of measuring cylinder. The cylinder was allowed to fall onto a hard surface from a height of $2.5 \mathrm{~cm}$ at $2 \mathrm{sec}$ intervals. The tapping was continued till no volume change was noted. $\rho_{\mathrm{u}}$ and $\rho_{\mathrm{b}}$ were determined by following formulas;

$$
\begin{aligned}
& \rho_{\mathrm{b}}=\frac{\mathbf{M}}{\mathrm{V}_{\mathrm{b}}} \\
& \boldsymbol{\rho}_{\mathrm{u}}=\frac{M}{\mathrm{~V}_{\mathrm{u}}}
\end{aligned}
$$

\section{(b) Carr's Compressibility Index:}

An important measure that can be obtained from bulk density determinations is the percent compressibility $\mathrm{C}$, which is defined as follows

$$
\mathrm{C}=\frac{\rho_{\mathrm{b}}-\rho_{\mathrm{u}}}{\rho_{\mathrm{b}}}(\mathbf{1 0 0})
$$

(c) Hausner ratio: A similar index has been defined by Hausner.

$$
\text { Hausner ratio }=\frac{\rho_{b}}{\rho_{u}}
$$

\section{(d) Angle of repose:}

The angle of repose of the powder blend was determined by using funnel method. The accurately weighed powder were taken in a funnel. The height of the funnel was adjusted in such a way that the tip of the funnel just touched the apex of the heap of the powder. The diameter of the powder cone was measured and angle of repose was ralculated hv " ising the equation

$$
\tan \boldsymbol{\theta}=\frac{\mathbf{h}}{\mathbf{r}}
$$

Where $\mathrm{h}$ and $\mathrm{r}$ are the height and radius of the powder cone.

Average values are shown in Table

Table 2: Standard values of angle of repose $(\theta)$.

\begin{tabular}{|c|c|}
\hline Flowability & Angle of repose \\
\hline Excellent & $<25$ \\
\hline Good & $25-30$ \\
\hline Passable $^{*}$ & $30-40$ \\
\hline Poor & $37-45$ \\
\hline Very poor & $>45$ \\
\hline
\end{tabular}

Evaluation of tablets ${ }^{20-25}$ :

\section{(a) Tablet thickness and size}

Thickness and diameter of tablets were important for uniformity of tablet size. Thickness and diameter was measured using Vernier callipers.

\section{(b) Tablet hardness}

The resistance of tablets to shipping or breakage, under conditions of storage, transportation and handling before usage depends on its hardness. The hardness of tablet of each formulation was measured by Monsanto hardness tester. The hardness was measured in terms of $\mathrm{kg} / \mathrm{cm}^{2}$.

\section{(c) Friability}

Friability is the measure of tablet strength. Roche type friabilator was used for testing the friability using the following procedure. Twenty tablets were weighed accurately and placed in the tumbling apparatus that revolves at $25 \mathrm{rpm}$ dropping the tablets through a distance of six inches with each revolution. After 4 min., the tablets were weighed and the percentage loss in tablet weight was determined.

Initial wt. of tablets - Final wt. of tablets $\%$ loss $=\frac{\text { Initial wt. of tablets }}{\mathrm{x}} \mathrm{100}$

\section{(d) Uniformity of weight}

Twenty tablets were selected at random and the average weight was calculated. Weight variation was calculated and was compared with I. P. standards.

\section{(e) Drug content}

Five tablets were weighed and powdered. The quantity equivalent to $500 \mathrm{mg}$ of cefuroxime axetil was weighed accurately and taken in 500-ml volumetric flask. 200 milliliters of $0.1 \mathrm{~N} \mathrm{HCl}$ was added, sonicated for $5 \mathrm{~min}$, made up to $500 \mathrm{ml}$ with $0.1 \mathrm{~N} \mathrm{HCl}$, and filtered. From above solution further dilution was made and the drug concentration was determined at $278 \mathrm{~nm}$ by using UV spectrophotometer. Drug content was calculated by using absorbance at wavelength $280 \mathrm{~nm}$. The results obtained were compared with I. P. standards.

\section{(f) Matrix integrity}

Matrix integrity was observed throughout in vitro dissolution studies and the swollen mass of the tablets remain intact or not was checked.

\section{(g)Buoyancy lag time}

This test was performed in beaker containing $200 \mathrm{ml} \mathrm{pH}$ 1.2 buffer as a testing medium maintained at $37^{\circ} \mathrm{C}$. The time required for the tablet to rise to the surface and float was determined as buoyancy lag time.

\section{(h) The duration of Buoyancy time}

The time, for which the tablet constantly floats on the surface of the medium, duration of buoyancy, was measured. The duration of buoyancy was determined using a USP dissolution apparatus Type II containing $900 \mathrm{~mL}$ of $0.1 \mathrm{~N} \mathrm{HCL}$ at $50 \mathrm{rpm}$. 


\section{(i) Swelling behaviour}

The swelling index of tablet was determined in $900 \mathrm{ml}$ Glycin ( $\mathrm{pH} 3$ ) using USP dissolution apparatus Type II at $75 \mathrm{rpm}$. The medium was maintained at $37 \pm 0.5 \circ \mathrm{C}$ throughout the study
tablet was withdraw Swelling index $=$ and weighed. Swelli $\quad \mathrm{W}_{0}$ st was expressed in terms o

where $\mathrm{W}_{0}$ is the initial weight of tablet, \& $\mathrm{W}_{\mathrm{t}}$ is the weight of tablet at time $\mathrm{t}$.

\section{(j) In vitro dissolution studies}

The release rate of cefuroxime axetil from matrix tablets was determined using USP dissolution testing apparatus II (Paddle type). The dissolution test was performed using $900 \mathrm{ml}$ of $0.1 \mathrm{~N} \mathrm{HCL}$, at $37 \pm 0.5^{\circ} \mathrm{C}$ and $50 \mathrm{rpm}$. A $5 \mathrm{ml}$ sample solution was withdrawn from the dissolution apparatus for $30 \mathrm{~min}, 1 \mathrm{hr}$ and there after every hour for $12 \mathrm{hrs}$. Samples were replaced by its equivalent volume of dissolution medium. The samples were filtered through Whatman filter paper and solutions were analyzed at $280 \mathrm{~nm}$ by UV Spectrophotometer (Libindia Disso-2000). Cumulative percentage drug release was calculated.

\section{Drug release kinetics}

Dissolution data of above two methods was fitted in Zero order, First order and Higuchi equations.

The mechanism of drug release was determined by using Korsmayer Peppas equation.

\section{Zero-Order Kinetics:}

Zero order as cumulative amount of drug released vs time,

$$
\mathbf{C}=\mathbf{K}_{\mathbf{0}} \mathbf{t}
$$

Where $K_{0}$ is the zero-order rate constant expressed in units of concentration/time and $t$ is the time in hours. A graph of concentration vs time would yield a straight line with a slope equal to $K_{0}$ and intercept the origin of the axes.

\section{First order kinetics:}

First order as log cumulative percentage of drug remaining vs time,

$$
\log C=\log C_{o}-k t / 2.303
$$

Where $C_{0}$ is the initial concentration of drug, $k$ is the first order constant, and $t$ is the time.

\section{Higuchi Model:}

Higuchi's model as cumulative percentage of drug released vs square root of time

$\mathbf{Q}=K \mathbf{t}^{1 / 2}$

Where $K$ is the constant reflecting the design variables of the system and $t$ is the time in hours. Hence, drug release rate is proportional to the reciprocal of the square root of time.

\section{Korsmayer Peppas equations:}

To evaluate the mechanism of drug release from Disulfiram implant, data for the first $60 \%$ of drug release were plotted in Korsmeyer et al's equation log cumulative percentage of drug released vs log time, and the exponent $n$ was calculated through the slope of the straight line.

$$
M \mathbf{t} / \mathbf{M} \infty=\mathbf{K} \mathbf{t} \mathbf{n}
$$

where $M_{t} / M_{\infty}$ is the fractional solute release, $t$ is the release time, $K$ is a kinetic constant characteristic of the drug/polymer system, and $n$ is an exponent that characterizes the mechanism of release of tracers. For cylindrical matrix tablets, if the exponent $n=0.45$, then the drug release mechanism is Fickian diffusion, and if $0.45<n<0.89$, then it is non-Fickian or anomalous diffusion. An exponent value of 0.89 is indicative of Case-II Transport or typical zero-order release.

\section{RESULTS AND DISCUSSION PREFORMULATION STUDIES}

\section{Characterization of cefuroxime axetil}

\section{A. Organoleptic properties}

The sample of cefuroxime axetil was found to be a yellowish white to light white crystalline powder. It has characteristic odor and bitter test.

\section{B. Melting point}

The melting point of cefuroxime axetil was found to be in the range of $218-225^{\circ} \mathrm{C}$

\section{FTIR spectroscopy}

The FTIR spectrum is shown in Figure 1 and interpretation of FTIR spectra is given in Table 3.FTIR spectrum of cefuroxime axetil showed all the peaks corresponding to the functional groups present in the structure of cefuroxime axetil. 


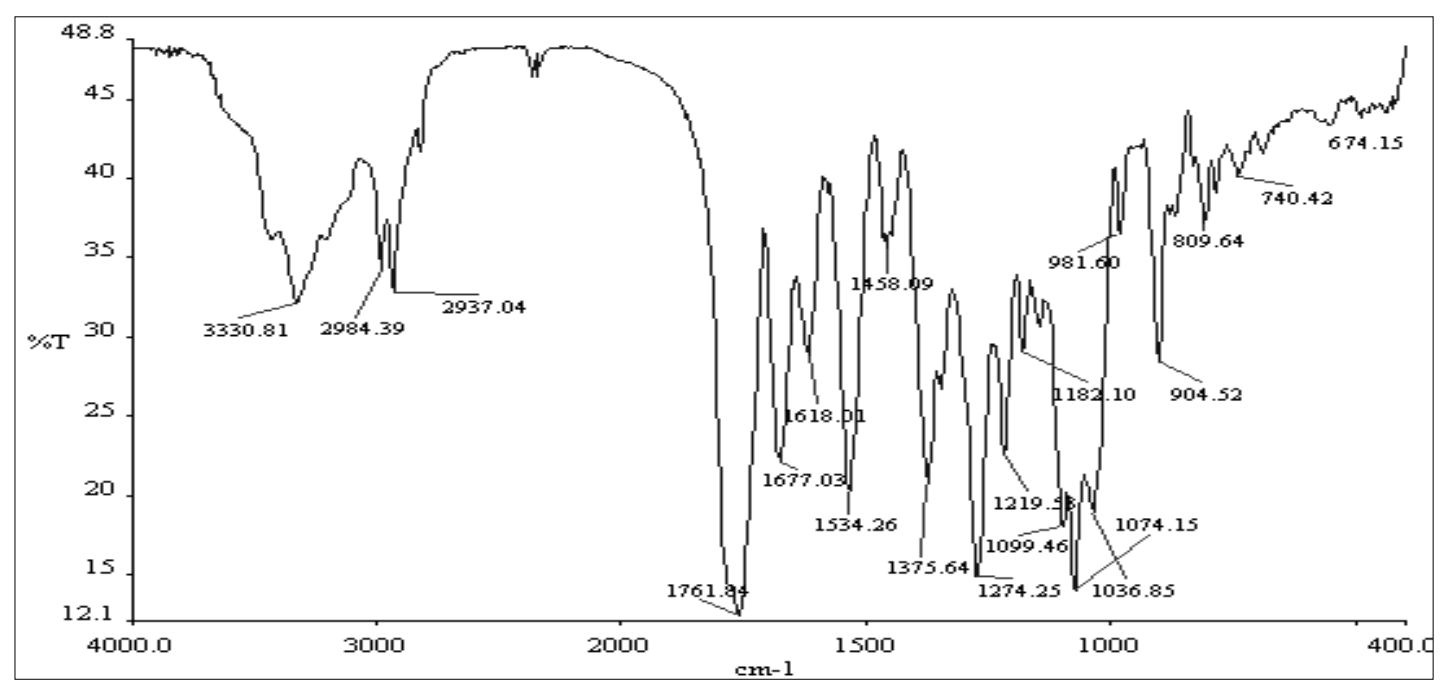

Figure 1: FTIR spectrum of cefuroxime axetil

Table 3: Interpretation of FTIR spectrum of Cefuroxime Axetil

\begin{tabular}{|l|l|l|}
\hline S.N. & Peak observed $\left.\mathbf{( c m}^{-1}\right)$ & Interpretation \\
\hline & 2937 & C-H stretching(aliphatic) \\
\hline & 2984 & C-H stretching(aromatic) \\
\hline & 3330 & N-H stretching \\
\hline & 1618 & N-H bending \\
\hline & 1074,1099 & C-O stretching \\
\hline & 1761 & C=O stretching \\
\hline & 674 & C-S-C stretching \\
\hline & 1274 & C-N stretching \\
\hline
\end{tabular}

\section{UV spectroscopy (Determination of $\lambda_{\max }$ )}

Wavelength of maximum absorbance $\left(\lambda_{\max }\right)$ of cefuroxime axetil was found to be $280 \mathrm{~nm}$ in $0.1 \mathrm{~N}$ HCL. The UV spectrum is shown in Figure 2

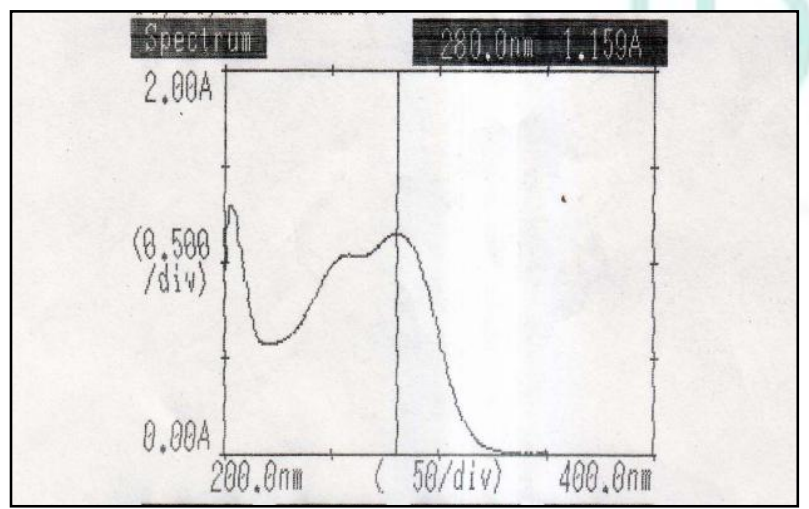

Figure 2: UV spectrum of Cefuroxime Axetil

\section{Calibration curve for cefuroxime axetil}

The calibration curve for cefuroxime axetill in $0.1 \mathrm{~N}$ HCL is shown in Figure 3 . The graph of absorbance vs. concentration for cefuroxime axetil was found to be linear in the concentration range of $5-30 \mu \mathrm{g} / \mathrm{ml}$ at 280 $\mathrm{nm}$. The $\mathrm{r}^{2}$ of the calibration curve was found to be 0.997

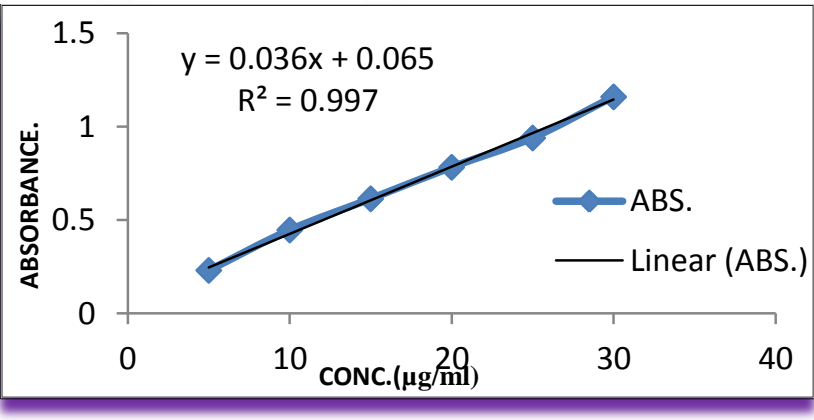

Figure 3: Calibration curve for cefuroxime axetil 


\section{E. Differential Scanning Calorimetry study}

Differential Scanning Calorimetry studies indicated a sharp endothermic peak at $210^{\circ} \mathrm{C}$ for pure cefuroxime axetil.

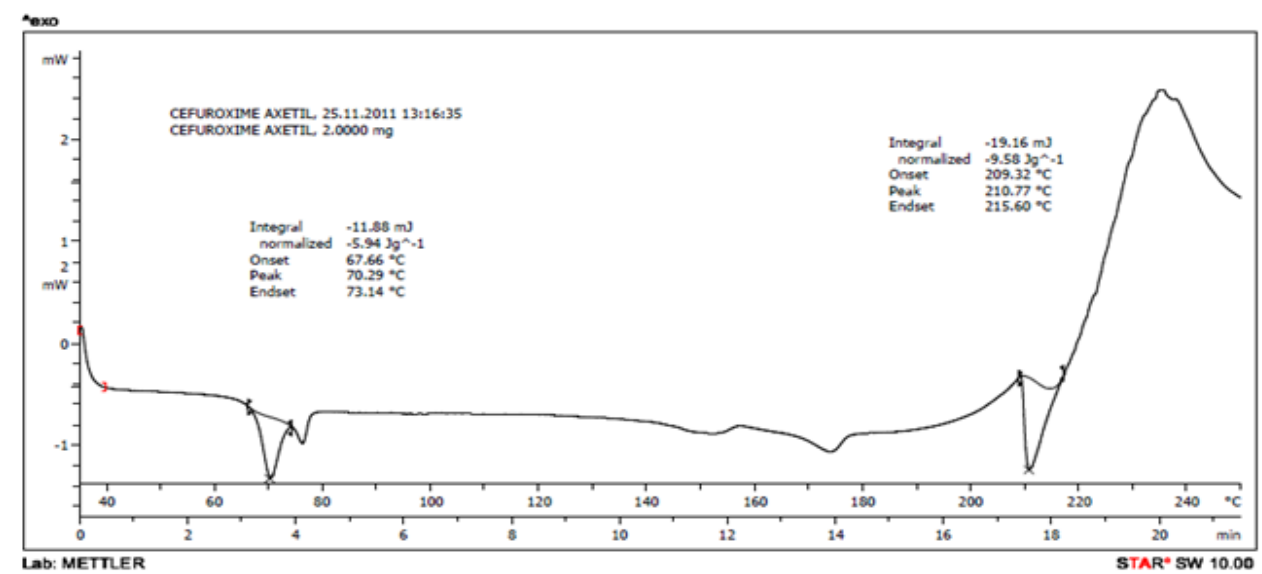

Figure 4: DSC graph of cefuroxime axetil

\section{G. Solubility:}

Cefuroxime axetil soluble in acetone, ethanol, and in chloroform. It is slightly soluble In Dehydrate Alcohol. Cefuroxime axetil insoluble in water.

\section{H. Drug Excipients Interaction}

FTIR is called as fingerprint technique and is widely used in identification of drugs and excipients. The FTIR spectra of drug was compared with FTIR spectra of drug and excipients mixture. There was no significant change in the position of this peak in the FTIR spectra of drug and excipients mixture. So it can be concluded that the excipients and drug do not interact with each other.

DSC thermograms of drug and polymer samples showed the peaks at $215.60^{\circ} \mathrm{C}$ and $195.30^{\circ} \mathrm{C}$ respectively. These are the temperatures corresponding to the melting points of Cefuroxime axetil and polymers respectively. There was no significant change in the position of this peak in the thermograms of drug and excipients mixture. So it can be concluded that the excipients and drug do not interact with each other.

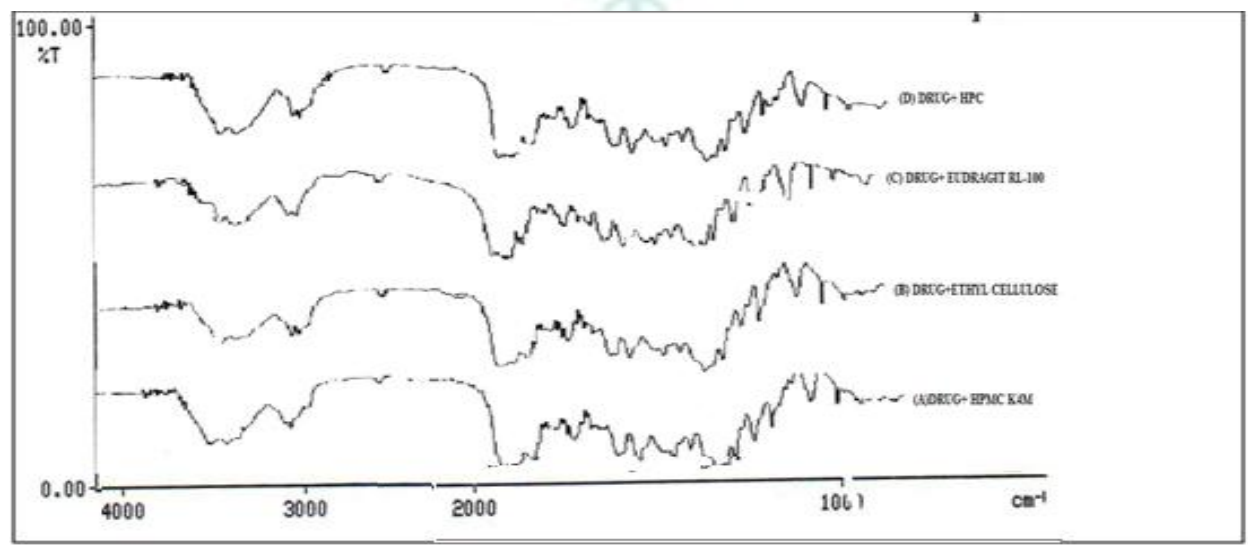

Figure 5: Comparative study of drug and excipients by FTIR spectrum (A)Drug+HPMC K4M (B) Drug+ethyl cellulose(C) Drug+Eudragit RL-100(D) Drug+HPC

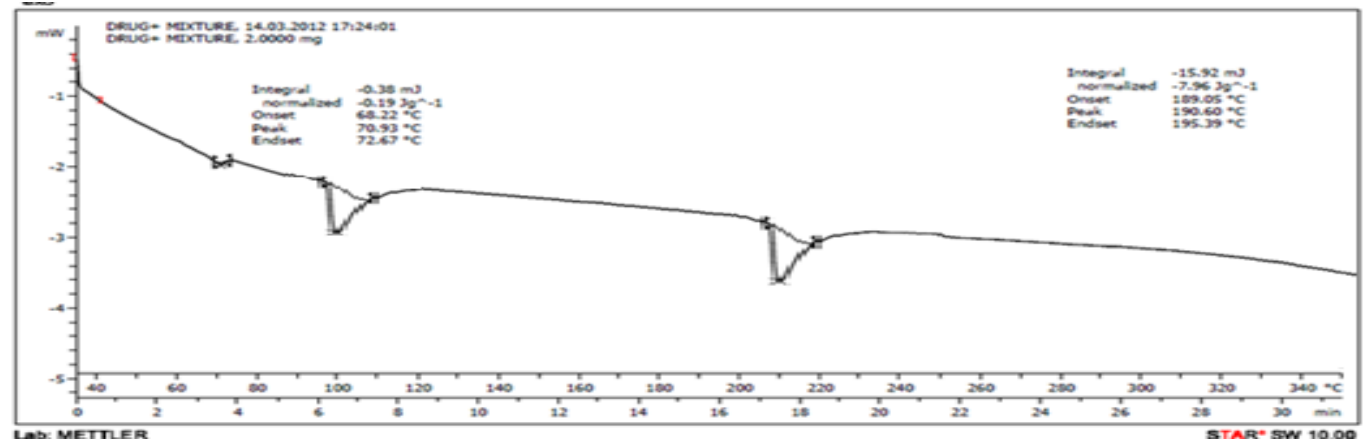

Figure 6: DSC graph of cefuroxime axetil+HPMC K4 M+Ethyl cellulose+Eudragit RL 100+Hydroxy propyl cellulose 
Evaluation of granules:

Table 4: Evaluation of granules

\begin{tabular}{|c|c|c|c|c|c|}
\hline Formulations & $\begin{array}{c}\text { Bulk Density } \\
\text { (g/cc) }\end{array}$ & $\begin{array}{c}\text { Tapped Density } \\
\text { (g/cc) }\end{array}$ & $\begin{array}{c}\text { Carr's compressibility } \\
\text { index }\end{array}$ & $\begin{array}{c}\text { Hausner's } \\
\text { ratio }\end{array}$ & $\begin{array}{c}\text { Angle of repose } \\
\text { (degree) }\end{array}$ \\
\hline F1 & 0.211 & 0.380 & 0.444 & 1.800 & 35.68 \\
\hline F2 & 0.221 & 0.387 & 0.428 & 1.751 & 42.30 \\
\hline F3 & 0.214 & 0.378 & 0.433 & 1.766 & 35.68 \\
\hline F4 & 0.229 & 0.370 & 0.381 & 1.615 & 35.68 \\
\hline F5 & 0.22 & 0.367 & 0.400 & 1.668 & 41.34 \\
\hline F6 & 0.218 & 0.390 & 0.441 & 1.788 & 35.68 \\
\hline F7 & 0.221 & 0.385 & 0.462 & 1.859 & 40.69 \\
\hline
\end{tabular}

\section{EVALUATION OF TABLETS}

\section{(A)Tablet thickness and size}

Size of formulations was found to be 9.5 to $11.5 \mathrm{~mm}$. Thickness was found to be 5.0 to $5.4 \mathrm{~mm}$ for all the formulations. Every measurement was made in triplicate.

Table 5: Tablet thickness and size

\begin{tabular}{|c|c|c|}
\hline Formulations & Thickness(mm) & Diameter(mm) \\
\hline F1 & 5.0 & 10.5 \\
\hline F2 & 5.2 & 11.2 \\
\hline F3 & 5.2 & 9.5 \\
\hline F4 & 5.3 & 11.5 \\
\hline F5 & 5.4 & 10.9 \\
\hline F6 & 5.4 & 11.2 \\
\hline F7 & 5.3 & 11.5 \\
\hline
\end{tabular}

\section{(B)Tablet hardness}

Hardness of tablets of each formulation was measured and was found in the range of $3-5 \mathrm{~kg} / \mathrm{cm}^{2}$. Each sample was analyzed in triplicate.

(C)Friability

Percentage weight loss of the tablets of each formulation was measured and was found to be less than $1 \%$ for all the formulations

(E)Uniformity of weight

Tablets from each batch showed uniformity of weight as per I. P. limits. Average weight of the tablet was found to be from $482 \mathrm{mg}$ to $500 \mathrm{mg}$ for all formulations

Table 6: Tablet hardness, friability and average weight

\begin{tabular}{|l|l|l|l|}
\hline Formulations & Hardness $\mathbf{( k g / \mathbf { c m } ^ { 2 } )}$ & Friability $\mathbf{( \% )}$ & Average weight $(\mathbf{m g})$ \\
\hline F1 & 3.8 & 0.21 & 482 \\
\hline F2 & 4.2 & 0.43 & 497 \\
\hline F3 & $3 . .6$ & 0.28 & 500 \\
\hline F4 & 4.3 & 0.30 & 489 \\
\hline F5 & 3.8 & 0.47 & 493 \\
\hline F6 & 4.6 & 0.49 & 490 \\
\hline F7 & 4.3 & 0.51 & 487 \\
\hline
\end{tabular}

(F) Drug content

All tablets formulations showed $94.16 \%$ to $100.86 \%$ drug content. Tablets from each batch showed uniformity of content as per I.P limit

\section{(G)Buoyancy lag time}

Increasing the polymer concentration decreased the buoyancy lag time. Carbon dioxide which was liberated by the reaction of the sodium bicarbonate with the acidic environment of the gastric contents is entrapped in the gellified hydrocolloid. This produced an upward motion of the dosage form and maintains its buoyancy.
Buoyancy lag time for all formulations was found to be less than $1 \mathrm{~min}$.

Table 7: Drug content

\begin{tabular}{|l|l|}
\hline Formulation & Assay \\
\hline F1 & $94.16 \%$ \\
\hline F2 & $99.23 \%$ \\
\hline F3 & $100.86 \%$ \\
\hline F4 & $98.27 \%$ \\
\hline F5 & $96.80 \%$ \\
\hline F6 & $95.26 \%$ \\
\hline F7 & $99.86 \%$ \\
\hline
\end{tabular}




\section{(H) Buoyancy time}

Total floating time of all formulations is shown in Table

Table 8: Buoyancy Lag Time

\begin{tabular}{|l|l|l|l|l|l|l|l|}
\hline $\begin{array}{l}\text { Formulation } \\
\text { code }\end{array}$ & F1 & F2 & F3 & F4 & F5 & F6 & F7 \\
\hline $\begin{array}{l}\text { Time } \\
\text { (second) }\end{array}$ & 4 & 3 & 2.5 & 9 & 8 & 5 & 2 \\
\hline
\end{tabular}

Table 9: Total floating time

\begin{tabular}{|c|c|}
\hline Formulation & TFT (hrs) \\
\hline F1 & $>12$ \\
\hline F2 & 10.5 \\
\hline F3 & 9.5 \\
\hline F4 & 11.5 \\
\hline F5 & 12 \\
\hline F6 & 12 \\
\hline F7 & $>12$ \\
\hline
\end{tabular}

(I) Swelling Index of Tablet

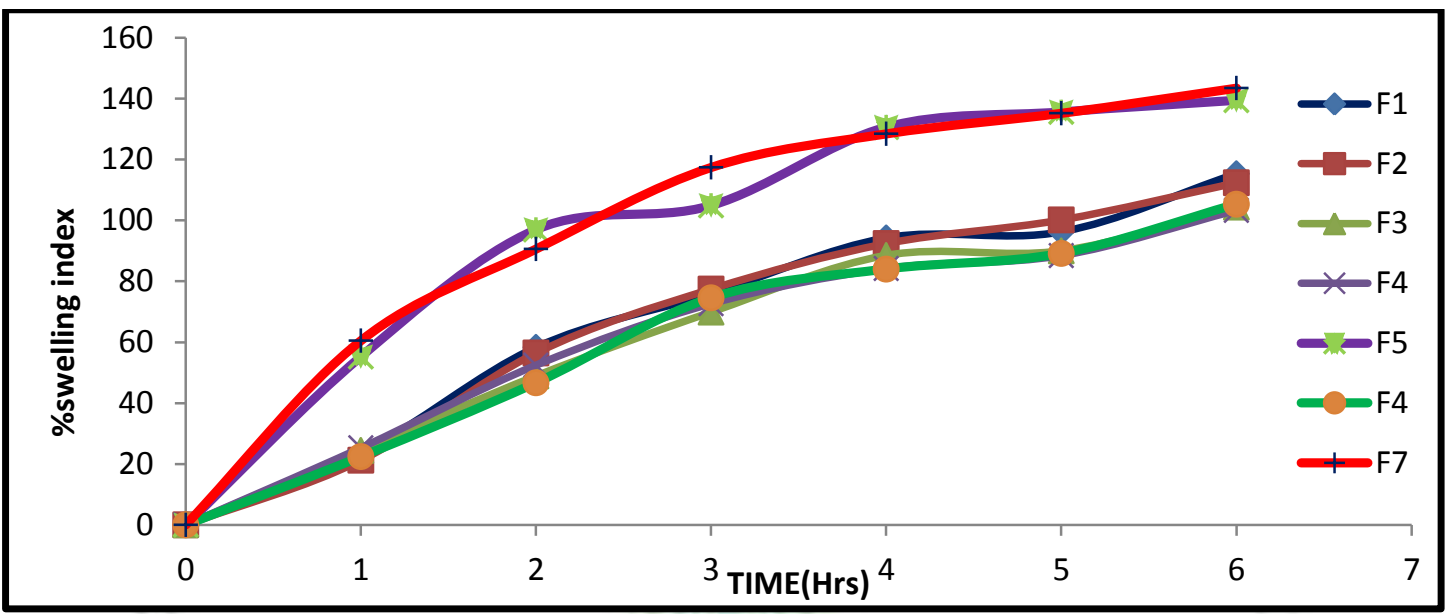

Figure 7: Swelling behavior of formulations F1 to F7.

In vitro dissolution studies

Table 10: Cumulative \% drug released from floating tablet formulations of F1-F7

\begin{tabular}{|l|l|l|l|l|l|l|l|}
\hline \multirow{2}{*}{$\begin{array}{c}\text { Time } \\
\text { Hours) }\end{array}$} & \multicolumn{7}{|c|}{ Cumulative \% release } \\
\cline { 2 - 8 } & $\mathbf{7}$ & $\mathbf{F}$ & $\mathbf{F 3}$ & $\mathbf{F 4}$ & $\mathbf{F 5}$ & F6 & F7 \\
\hline $\mathbf{1}$ & 12.433 & 7.417 & 10.432 & 12.15056 & 15.15722 & 6.411111 & 4.102222 \\
\hline $\mathbf{2}$ & 13.10278 & 9.858333 & 14.390 & 17.21778 & 19.54111 & 13.04667 & 12.125 \\
\hline $\mathbf{3}$ & 14.575 & 15.41278 & 19.96944 & 22.61278 & 28.54889 & 16.41889 & 14.89222 \\
\hline $\mathbf{4}$ & 18.055 & 19.09778 & 26.67944 & 28.43722 & 33.80611 & 22.60944 & 24.07444 \\
\hline $\mathbf{5}$ & 22.05389 & 21.60278 & 32.42611 & 33.39333 & 36.69167 & 27.53389 & 31.90722 \\
\hline $\mathbf{6}$ & 24.47444 & 25.52111 & 36.80389 & 40.97611 & 42.49222 & 33.585 & 39.58278 \\
\hline $\mathbf{7}$ & 39.30778 & 30.96056 & 40.505 & 45.6 & 48.02389 & 37.06889 & 50.4 \\
\hline $\mathbf{8}$ & 50.62278 & 36.02944 & 47.42556 & 51.74833 & 57.985 & 43.17111 & 61.37611 \\
\hline $\mathbf{9}$ & 58.39944 & 42.92556 & 54.38333 & 58.82944 & 64.9 & 48.20611 & 70.11167 \\
\hline $\mathbf{1 0}$ & 63.31778 & 48.85889 & 57.67833 & 65.54833 & 71.75167 & 54.36778 & 77.89389 \\
\hline $\mathbf{1 1}$ & 66.16167 & 55.72389 & 60.59 & 69.30278 & 78.43944 & 58.36222 & 88.21722 \\
\hline $\mathbf{1 2}$ & 73.91944 & 64.52556 & 65.91611 & 74.57611 & 89.76222 & 64.07722 & 99.59556 \\
\hline
\end{tabular}

\section{Drug release kinetics:}

Drug release profiles of the formulations were determined by fitting the dissolution data to zero order, first order and Higuchi equation. The equation for which the highest $\mathrm{R}^{2}$ was obtained was considered as the best fit release profile. The mechanism of drug release was determined by fitting the drug release data to Korsmeyer's Peppas equation. The detail data treatment is presented in the next section.

\section{Drug Release Kinetics}

For all the formulation Korsmeyer's Peppas exponent (n) was found to be greater than $0.5(>0.5)$. This indicated that mechanism of drug release controlled from the Cefuroxime Axetil floating tablet was based on diffusion as well as erosion phenomenon. The in vitro release kinetics exhibited a non-Fickian transport model. This kind of diffusion corresponds to a more predictable type of swelling-controlled system. 
Table 11: Drug release kinetics of all formulation

\begin{tabular}{|c|c|c|c|c|c|c|c|c|}
\hline Formulations & \multicolumn{2}{|c|}{ Zero order } & \multicolumn{2}{c|}{ First order } & \multicolumn{2}{c|}{ Higuchi equation } & \multicolumn{2}{c|}{ Korsmeyar's Peppas } \\
\hline & $\begin{array}{c}\text { Equation of } \\
\text { line }\end{array}$ & $\begin{array}{c}\text { Reg. } \\
\text { coef }\end{array}$ & $\begin{array}{c}\text { Equation of } \\
\text { line }\end{array}$ & $\begin{array}{c}\text { Reg. } \\
\text { coef }\end{array}$ & $\begin{array}{c}\text { Equation of } \\
\text { line }\end{array}$ & $\begin{array}{c}\text { Reg } \\
\text { coef. }\end{array}$ & $\begin{array}{c}\text { Equation of } \\
\text { line }\end{array}$ & $\begin{array}{c}\text { Reg. } \\
\text { Coef. }\end{array}$ \\
\hline F1 & $0.101 x-1.274$ & $\mathbf{0 . 9 5 1}$ & $0.001 x+0.998$ & $\mathbf{0 . 9 5 0}$ & $3.246 x-22.37$ & 0.868 & $0.771 x-0.429$ & 0.893 \\
\hline F2 & $0.082 x-0.799$ & $\mathbf{0 . 9 8 0}$ & $0.001 x+0.773$ & $\mathbf{0 . 9 0 0}$ & $2.680 x-18.53$ & 0.913 & $0.894 x-0.822$ & 0.982 \\
\hline F3 & $0.087 x+4.787$ & $\mathbf{0 . 9 9 5}$ & $0.001 x+$ & $\mathbf{0 . 8 8 4}$ & $2.885 x-15.11$ & 0.976 & $0.767 x-0.389$ & 0.993 \\
& & & 0.987 & & & & & 0.997 \\
\hline F4 & $0.096 x+5.656$ & $\mathbf{0 . 9 9 8}$ & $0.001 x+1.078$ & $\mathbf{0 . 9 3 4}$ & $3.174 x-15.92$ & 0.961 & $0.693 x-0.148$ & $0.997 x-140$ \\
\hline F5 & $0.109 x+6.448$ & $\mathbf{0 . 9 9 0}$ & $0.001 x+1.146$ & $\mathbf{0 . 9 3 8}$ & $3.549 x-17.40$ & 0.940 & $0.671 x-0.040$ & 0.974 \\
\hline F6 & $0.087 x$ & $\mathbf{0 . 9 9 8}$ & $0.001 x+0.769$ & $\mathbf{0 . 7 9 9}$ & $2.795 x-18.84$ & 0.973 & $1.018 x-1.087$ & 0.987 \\
\hline F7 & $0.143 x+7.727$ & $\mathbf{0 . 9 9 2}$ & $0.002 x+0.595$ & $\mathbf{0 . 8 0 8}$ & $4.644 x-38.68$ & 0.933 & $1.374 x-1.905$ & 0.990 \\
\hline
\end{tabular}

From the results shown in Table 11, we can conclude that,

The overall order of release data of drug from implant, fitting in different mathematical model is as follows,

\section{F1 BATCH:}

Zero order $>$ First order $>$ Korsmeyer Peppas $>$ Higuchi

\section{F2 BATCH:}

Zero order $>$ Korsmeyer Peppas $>$ Higuchi $>$ First order

\section{F3 BATCH}

Zero order $>$ Korsmeyer Peppas $>$ Higuchi $>$ First order

\section{F4 BATCH:}

Zero order $>$ Korsmeyer Peppas $>$ Higuchi $>$ First order

\section{F5 BATCH:}

Zero order $>$ Korsmeyer Peppas $>$ Higuchi $>$ First order

\section{F6 BATCH:}

Zero order > Korsmeyer Peppas > Higuchi > First order

\section{F7 BATCH:}

Zero order > Korsmeyer Peppas > Higuchi > First order

Release rate constant: The release rate constant $(\mathrm{k})$ of Zero order and First order for in vitro drug release of all formulations are given below in table 12

Table 12: Zero order and first order release rate constants

\begin{tabular}{|l|l|l|}
\hline Formulation & \multicolumn{2}{|c|}{ Release Rate Constant } \\
\hline & Zero Order & First Order \\
\hline F1 & 0.232 & 0.002 \\
\hline F2 & 0.191 & 0.002 \\
\hline F3 & 0.200 & 0.002 \\
\hline F4 & 0.214 & 0.002 \\
\hline F5 & 0.251 & 0.002 \\
\hline F6 & 0.200 & 0.002 \\
\hline F7 & 0.329 & 0.004 \\
\hline
\end{tabular}

\section{Release Profile Comparison:}

For the present study an attempt was made to prepare the GRDDS of Cefuroxime Axetil with 4 different polymers and their combinations. The study reveals that the drug release from formulations is depend upon the swelling, molecular weight and diffusion ability of polymers. From the observation it is concluded that formulation containing HPMC K4M and HPC i.e F1 \& F4 shows the better release rate as it is used alone and having good swelling properties.

The batches F1, F5, F6 and F7 were prepared using polymers HPMC K4M, HPMC K4M: Ethyl Cellulose, HPMC K4M:Eudragit RL100 and HPMC K4M: HPC respectively and Floating tablets were prepared for each batch.

The drug release rate decreased in the rank order;

\section{F7 $>$ F5 > F1 > F6}

This can probably be attributed to the different diffusion and swelling behavior of the combination of these polymers. With increasing molecular weight, the degree of entanglement of polymer chain increases. Thus, the mobility of the drug molecules in the fully swollen systems decreases. This leads to decreased drug diffusion coefficients and decreased drug release rate with increase molecular weight. It is stated that a faster and greater drug release was expected for reasons with the evolution of gas, the matrix would become more relaxed allowing water penetration and diffusion of drug might be easier.

The drug release from F6 (HPMC K4M: Eudragit RL 100) shows that, as HPMC K4M used in combination with eudragit RL 100, the drug release of formulation is decreases as compare to F1 (HPMC K4M). This is because of the swelling properties of polymers.

From the above observation it is concluded that formulation F7 (HPMC-K: HPC) is the best formulation among all other 6 formulations because it is showing very controlled release of drug from Tablet formulations 


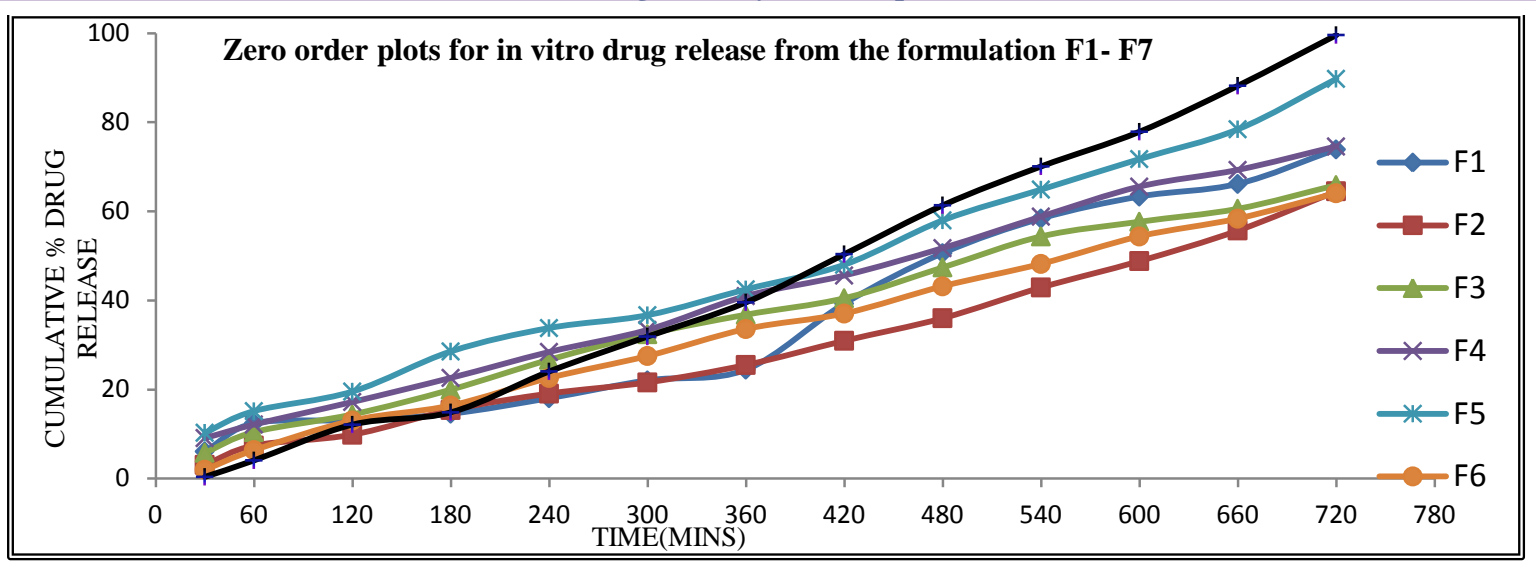

Figure 8: Zero order plots of the in vitro drug release from the formulations F1-F7

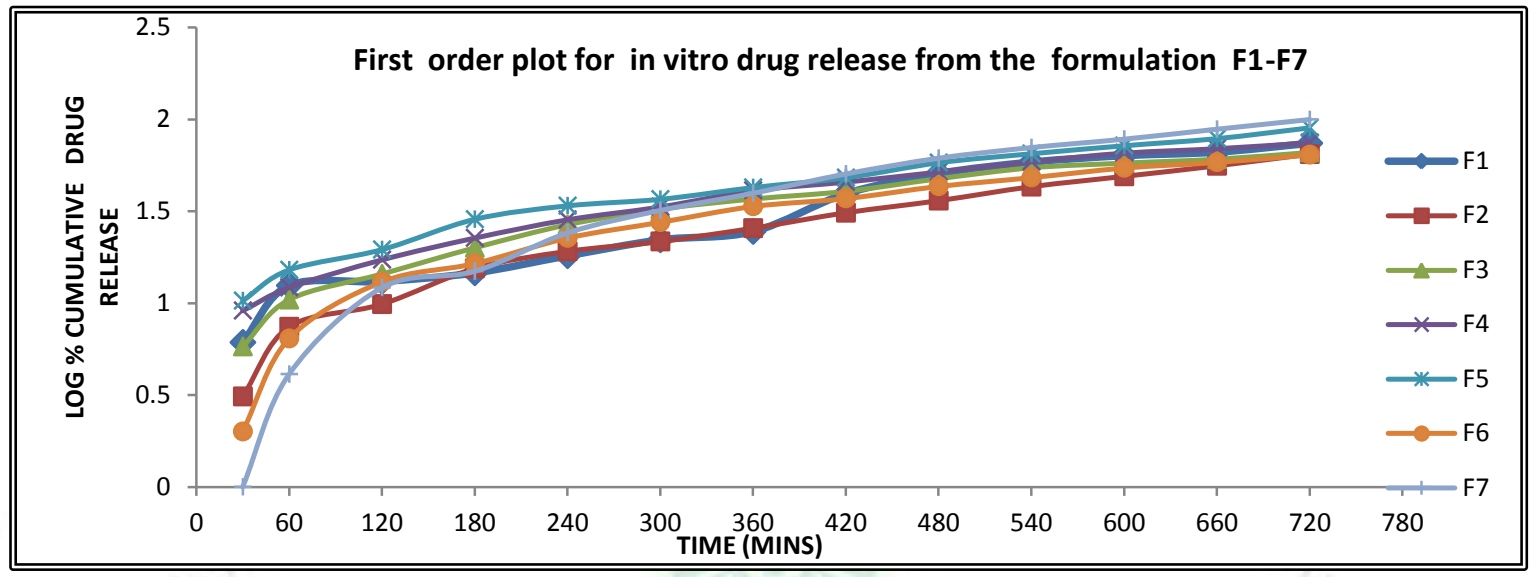

Figure 9: First order plots of the in vitro drug release from the formulations F1-F7

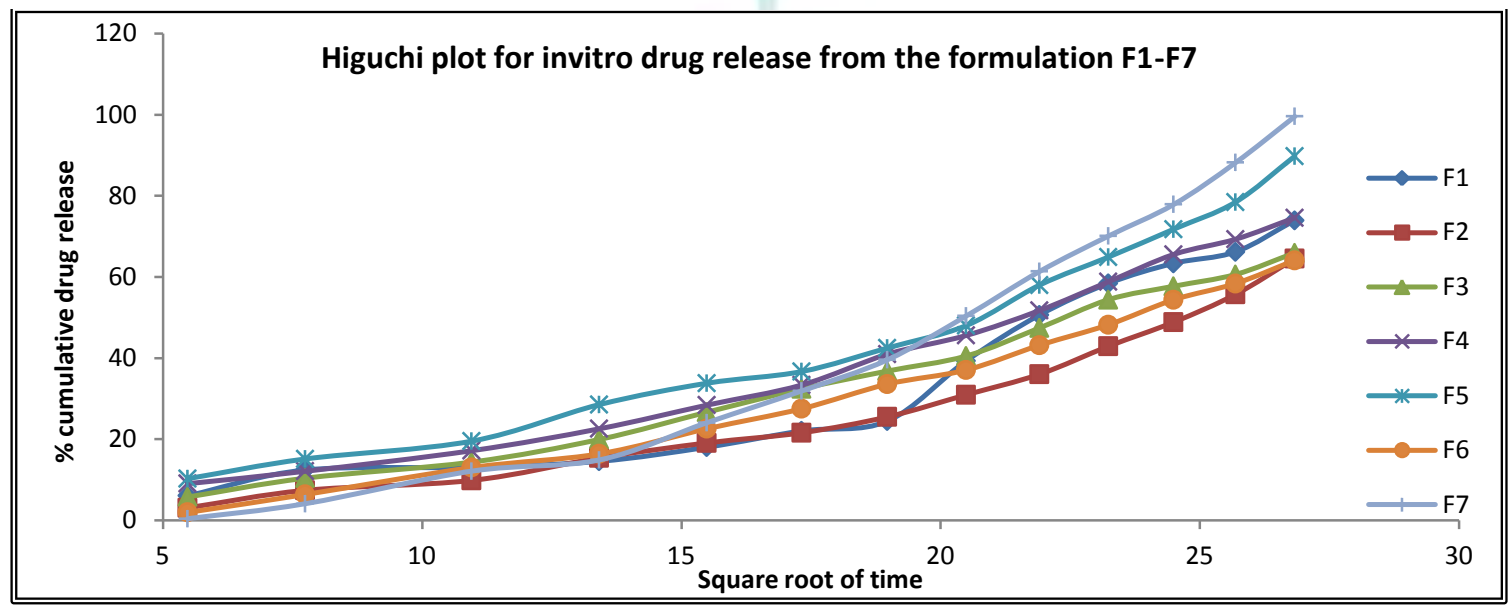

Figure: 10: Higuchi plots of the in vitro drug release from the formulations F1-F7

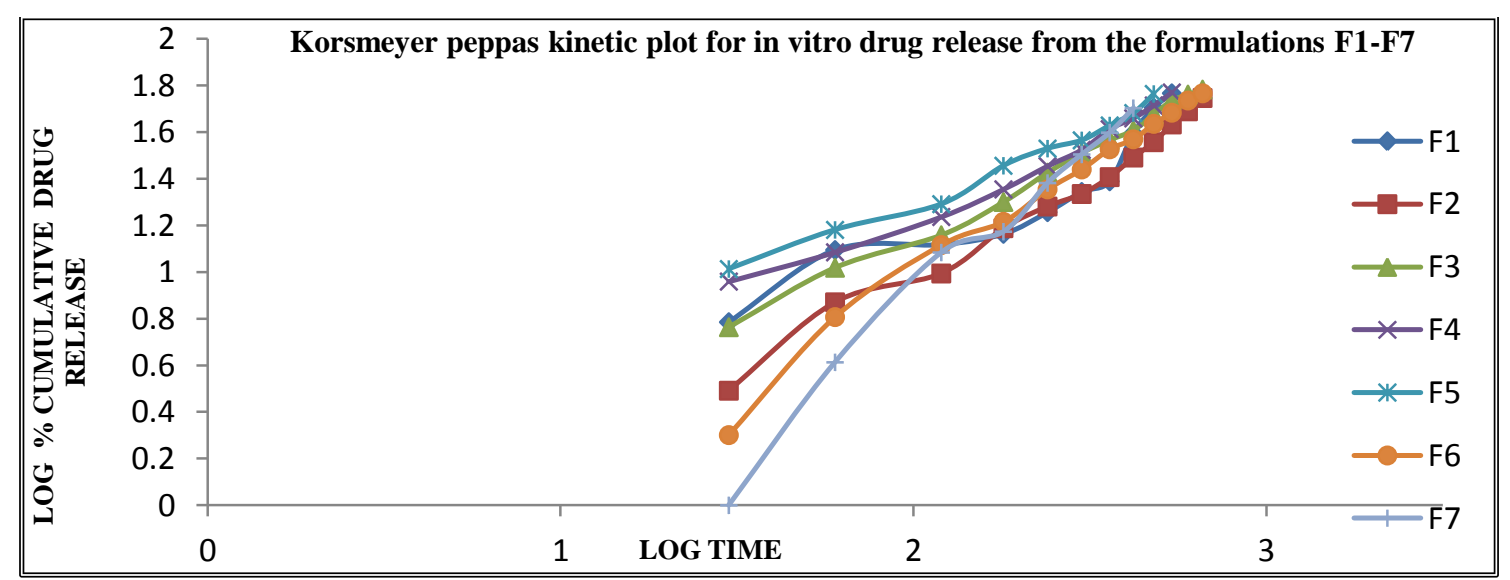

Figure 11: Korsmeyers peppas plots of the in vitro drug release from the formulations F1-F7 


\section{CONCLUSION:}

In the present study gastro-retentive floating tablets of cefuroxime axetil were successfully prepared by wet granulation method using polymer HPMC K4M, EC, EUDRAGIT RL100 and HPC for sustained release of therapeutically active agent, cefuroxime axetil in upper part of gastro-intestinal tract in the form of floating tablet.. From the above observation it is concluded that formulation F7 (HPMC-K: HPC) is the best formulation among all other 6 formulations because it is showing very controlled release of drug from Tablet formulations.

\section{REFRENCES:}

1. Chawla G, Gupta P, Bansal AK.Gastroretentivedrug deliverysystems. In: Jain NK, editor. Progress in controlled and noveldrug delivery system. $1^{\text {st }}$ ed.New Delhi (India): CBS Publishers and Distributors; 2004. p. 76-97.

2. Arora S, Ali J, Ahuja A, Khar RK, Baboota S. Floating drugdeliverysystems:AReview.AAPS PharmSciTech 2005; 6: Article 47.

3. Vyas SP, and KharRK.eds. Controlled Drug Delivery Concept And Advances. New Delhi:Vallabh Prakashan. $1^{\text {st }}$ edition 2000:1, 54,155,196

4. Arora S, Javed A, Ahuja A, Khar RK, Baboota S. Floating drug delivery system: A review. AAPS PharmSciTech. 2005;6:Article47

5. http://www.drugs.com

6. Indian Pharmacopoeia. Government of India. Ministry of Health and Family Welfare. Vol. II Delhi: Controller of Publications. 1996.

7. Shinde A.J.,Patil M. S., More H.N., MoreFormulation and Evaluation of an Oral Floating Tablet of Cephalexin,Indian J.Pharm. Educ. Res. 44(3), Jul-Sep, 20

8. Narendra C, Srinath MS, Ganesh B. Optimization of bilayer floating tablet containing metoprolol tartrate as a model drug for gastric retention. AAPS PharmSciTech 2006;7(2):Article 34

9. Prajapati ST, Patel LD, Patel DM.Gastric floating matrix tablets: Design and optimization using combination of polymers. Acta Pharm 2008; 58:221-229.

10. Tokumura T., Machida Y., Preparation of amoxicillin intragastric buoyant sustained-release tablets and the dissolution characteristics, Journal of Controlled Release. 2006; 110: 581-586

11. Chavanpatil M, Jain P, Chaudhari S, Shear R, Vavia P. Novel sustained release, swellable and bioadhesivegastroretentive drug delivery system for ofloxacin.Int J Pharm 2005; 304:178 184.

12. Arza RA, Gonugunta CS, Veerareddy PR. Formulation and evaluation of floating gastroretentive ciprofloxacin hydrochloride tablets. AAPS PharmSciTech 2009 March; 10(1):220-226

13. Patel A, Ray S, Thakur S. In-vitro evaluation and optimization of controlled release floating drug delivery system of metformin hydrochloride. DARU 2006; 14(2):57-64
14. KawashimaY,TakeuchiH,YamamotoH.Gastrointestinalretentiv emicroparticulatesystemtoimprove oral drug delivery. In: Wise DL, editor. Handbook of pharmaceutical controlledrelease technology. New York: Marcell Dekker Inc; 2000. P. 505-25.

15. Fabregas JL, Claramunt J, Cucala J, Pous R, Siles A. In vitro testing of an antacid formulation with prolonged gastric residence time (Almagateflot coat). Drug DevInd Pharm 1994; 20:1199-1212.

16. Liu S, Wang N, Liu R. Oral modified release drug delivery for water insoluble drugs. In: Liu R, editor. Water insoluble drug formulation, 2nd ed. Boka Raton (FL): CRC press; 2008. p. 609-32.

17. Loganathan V, Saravanakumar T, Bhojwani A, Mullaichavam A, Nandgude T. Formulation, development and evaluation of Ofloxacin containing floating drug delivery system. Asian J Pharm 2006; 1:22-24.

18. Chen J, Blevins WE, Park H, Park K. Gastric retention properties of superporous hydrogel composites. J Control Rel 2000; 64(1-3):39-51

19. Sharma S, Pawar A. Low density multiparticulate system for pulsatile release of meloxicam. Int J Pharm 2006; 313:15058.

20. Loganathan V, Saravanakumar T, Bhojwani A, Mullaichavam A, Nandgude T. Formulation, development and evaluation of Ofloxacin containing floating drug delivery system. Asian J Pharm 2006;1:22-24Korsmeyer RW, Gurny R, Doelker E, Buri P, Peppas NA. Mechanisms of potassium chloride release from compressed, hydrophilic, polymeric matrices: effect of entrapped air. J Pharm Sci 1983; 72:1189-91.

21. Gander B, Gurny R, Doelker E. Matrices for controlled liberation of drugs from polymers. Pharm ActaHelv 1986; 61:130-34.

22. Doelker E, Peppas NA, editors. Hydrogels in Medicine and Pharmacy. Boca Raton (FL): CRC Press Inc; 1987. p. 115160.

23. R.K.,MohapatraS.,DashR.K.BarikB.B.,Preparation and in vitro charachterizationofCefuroximeaxetil Floating tablet. Drug Invention Today 2010; 2(10):457-459

24. Sangekar S, Vadino WA, Chaudry I, Parr A, Behin R, Digenis G. Evaluation of effect of food and specific gravity on tablets on gastric retention time. Int J Pharm 1987; $35: 187-191$.

25. Baumgartner S, Kristel J, Vreer F, Vodopivec P, Zorko B. Optimisation of floating matrix tablets and evaluation of their gastric residence time. Int J Pharm. 2000; 195:125-135

26. Chavanpatil M, Jain P, Chaudhari S, Shear R, Vavia P. Development of sustained release gastroretentive drug delivery system for ofloxacin: In-vitro and in-vivo evaluation. Int J Pharm. 2005; 304:178-184

27. Colombo P, Santi P, Bettini R, Brazel CS, Peppas NA. Drug release from swelling-controlled system. In: Wise DL, editor. Handbook of pharmaceutical controlled release technology. New York: Marcel Dekker Inc; 2000. p. 183-209.

28. Korsmeyer RW, Gurny R, Doelker E, Buri P, Peppas NA. Mechanisms of potassium chloride release from compressed, hydrophilic, polymeric matrices: effect of entrapped air. J Pharm Sci 1983; 72:1189-91 